\title{
CELULARES, APLICATIVOS E OPERADORES NA MENSURAÇÃO FLORESTAL
}

\author{
CELL PHONES, APPLICATIONS AND OPERATORS IN FOREST MEASUREMENT
}

\author{
Charlote Wink ${ }^{1}$, Suely Bezerra de Lima ${ }^{2}$, Rafaella de Angeli Curto ${ }^{3}$, \\ Emanuel José Gomes de Araújo 4 \\ ${ }^{1}$ Universidade Federal de Mato Grosso, Campus de Sinop, Sinop, MT, Brasil - \\ charlote.wink@gmail.com \\ 2Universidade Federal de Mato Grosso, Campus de Sinop, Sinop, MT, Brasil - \\ suelybezerradelima@gmail.com \\ ${ }^{3}$ Universidade Federal Rural do Rio de Janeiro, Seropédica, RJ, Brasil - \\ rafaellacurto@yahoo.com.br \\ ${ }^{4}$ Universidade Federal Rural do Rio de Janeiro, Seropédica, RJ, Brasil -ejgaraujo@gmail.com
}

RESUMO

A acesso as tecnologias têm permitido mensurar as árvores de forma rápida, com menor custo e precisão, igualando-se as medições com equipamentos tradicionais. O objetivo foi avaliar a precisão de celulares, aplicativos e operadores na mensuração da altura de árvores em plantio de eucalipto. A altura total foi mensurada em 54 árvores, localizadas em 18 parcelas distribuídas sistematicamente, por dois operadores, usando os aplicativos Measure Height ${ }^{\circledR}$ e o Hypsometer ${ }^{\circledR}$ e os celulares Samsung Galaxy J7 ${ }^{\circledR}$ e Motorola Moto G7 Power ${ }^{\circledR}$, comparada a altura real obtida com Hipsômetro Vertex IV ${ }^{\circledR}$. Os resultados foram analisados pelo teste de normalidade de Kolmogorov-Smirnov e teste de Dunnett, ambos a $1 \%$ de probabilidade, análise gráfica de resíduos e estatística complementar. A altura total real média foi 31,04m (desvio padrão de 1,93 e coeficiente de variação de 6,21\%), com distribuição normal (K-S d =0,07475 a 0,20142) e análise de variância $(p<0,0001)$, ambos significativos. Pelo teste de Dunnett, somente a altura total estimada pelo Measure Height ${ }^{\circledR}$ nos dois celulares diferiu da altura total real obtida pelo Vertex. Independentemente do celular, o aplicativo Hypsometer ${ }^{\circledR}$ se aproximou do valor real. O celular Samsung ${ }^{\circledR}$ e operador 2 foram mais eficientes na estimativa, devido a distribuição de resíduos ser menos tendenciosa e mais homogênea, com menor diferença entre a estimativa e o valor real. Portanto, a exatidão na medição da altura total das árvores depende do celular, especialmente das características dos sensores, que pode influenciar no desempenho dos aplicativos, bem como na habilidade do operador na mensuração florestal.

Palavras-chaves: Exatidão, Sensores, Tecnologia, Vertex.

\begin{abstract}
The access to technologies has allowed the trees to be measured quickly, with lower cost and precision, equaling measurements with traditional equipment. The objective was to evaluate the accuracy of cell phones, applications and operators in measuring the height of trees in eucalyptus plantations. The total height was measured in 54 trees, located in 18 plots systematically distributed, by two operators, using the Measure Height ${ }^{\circledR}$ and Hypsometer ${ }^{\circledR}$ applications and Samsung Galaxy $\mathrm{J}^{\circledR}{ }^{\circledR}$ and Motorola Moto G7 Power ${ }^{\circledR}$ cell phones, compared to the actual height obtained with a Vertex IV ${ }^{\circledR}$ Hypsometer. The results were analyzed using the Kolmogorv-Smirnov normality test and the Dunnett test, both at $1 \%$ probability, graphical residuals analysis and complementary statistics. The mean total height was $31.04 \mathrm{~m}$ (standard deviation of 1.93 and coefficient of variation of 6.21), with a normal distribution (KS $d=0.07475$ to 0.20142 ) and analysis of variance $(p<0.0001)$, both significant. By Dunnett's test, only the total height estimated by Measure Height ${ }^{\circledR}$ in the two cell phones differed from the actual total height obtained by Vertex ${ }^{\circledast}$. Regardless of mobile phone, the Hypsometer ${ }^{\circledR}$ app approach the real value. The Samsung ${ }^{\circledR}$ cell phone and operator 2 were more efficient in estimating, due to the distribution of waste being less biased and more homogeneous, with less difference between the estimate and the real value. Therefore, the accuracy in measuring the total height of trees depends on the cell phone, especially on the characteristics of the sensors, which can influence the performance of applications, as well as the operator's ability to measure forestry.
\end{abstract}

Keywords: Accuracy, Sensors, Technology, Vertex. 


\section{INTRODUÇÃO}

O conhecimento do crescimento das florestas é fundamental para atender o propósito das estratégias do manejo florestal (SILVA \& SOARES, 2003), o qual envolve o planejamento, ordenamento e otimização no uso dos recursos florestais (SANTOS et al., 2012), e garantidos pela medição acurada das variáveis dendrométricas, como o diâmetro e a altura das árvores.

Importante ao manejo florestal, a altura de árvores, junto com a variável diâmetro, auxilia na determinação do estoque de volume de madeira, bem como gera outras informações quali-quantitativas de florestas plantadas ou nativas, atuando como indicador de qualidade produtiva de um local garantindo assim o planejamento correto da exploração de madeira (SILVA et al., 2012).

A medição da altura das árvores pode ser executada de forma direta, por meio de vara, trena ou escalada, ou indireta quando o operador não tem contato com a árvore, sendo assim realizada a distância, utilizando aparelhos denominados hipsômetros, baseados por princípios geométricos e trigonométricos (FINGER, 2006), com nível de acurácia diferenciada dependendo da forma de medição (FELICIANO et al., 2016). A mensuração indireta pode ocasionar erros nas estimativas os quais estão relacionados com a visibilidade da copa das árvores, inclinação da árvore/ou terreno, a falta de manutenção e manuseio incorreto dos instrumentos de medição, ou estão relacionados aos operadores, visto que estes exigem treinamento e habilidade, podendo ocorrer problemas relacionados a visualização, a técnica incorreta na leitura dos valores nos aparelhos, bem como a operação incorreta dos instrumentos (SOARES et al., 2011). Assim, a medição de altura é uma atividade onerosa quando comparada a mensuração do diâmetro.

Contudo, atualmente já se tem disponível equipamentos com comprovada precisão e exatidão na medição da altura das árvores, como é o caso do Vertex ${ }^{\circledR}$, porém esses possuem preço elevado (BOŽıć et al., 2005) limitando sua utilização. Desse modo, busca-se constantemente alternativas viáveis economicamente, como o uso de celulares, que apresentam menor custo de aquisição e de fácil acesso (GICHAMBA \& LUKANDU, 2012).

Essa tecnologia permite atualmente, medir comprimento, ângulo, distância, altura, largura e área, mensurar pilhas de madeira, além de funcionar como bússola, GPS e aliado aos aplicativos desenvolvidos para área florestal, podem ser utilizados na mensuração da altura de árvores (VILLASANTE \& FERNANDEZ, 2014) que visa reduzir custos, a partir de sua eficácia (URBANO et al, 2014). Em compensação, essa facilidade em associar um aparelho pessoal para mensuração pode trazer consigo erros devido as características do celular utilizado.

Aplicativos relacionados à mensuração florestal baseiam-se em princípios trigonométricos envolvendo dois componentes principais, o giroscópio e o acelerômetro, os quais podem ser encontrados na maioria dos celulares (VILLASANTE \& FERNANDEZ, 2014).

O acelerômetro é capaz de captar mudanças no movimento, medindo a força da aceleração aplicada ao dispositivo nos três eixos, encontrada no centro do aparelho e que repassa informação ao aplicativo, transformando em valores de altura. Já o giroscópio permite a detecção da rotação ao longo de cada um dos três eixos (OLIVEIRA \& GONÇALVES, 2017).

Com o auxílio da câmera e do acelerômetro presentes nos aparelhos celulares, os aplicativos permitem estimar a altura por meio da mensuração da distância e ângulos usando equações trigonométricas básicas (VILLASANTE \& FERNANDEZ, 2014).

No entanto, tem-se a necessidade de verificar se a utilização de aplicativos disponíveis para obtenção de altura, geram dados satisfatórios em termos de precisão e exatidão (VILLASSANTE \& FERNANDEZ, 2014; BIJAK \& SARZYŃSKI, 2015; LAURO et al., 2018; CURTO et al., 2019).

Bijak \& Sarzyński (2015) ao analisar dois aplicativos de Smartphones em povoamento de Pinus, concluíram que eles produzem erros e que necessitariam de melhorias no software. Lauro et al. (2018) também não recomendaram o uso de um aplicativo de Smartphone para a obtenção de altura em sistema integrado, atribuindo a este resultado as características do Smartphone.

Estudos realizados por Curto et al. (2019), em fragmento de floresta nativa e por Harfouche et al. (2019) em plantio homogêneo e em árvores isoladas, indicam escolher um determinado aplicativo para um celular específico, uma vez que dependendo do aparelho celular, os aplicativos podem gerar resultados de estimativa diferentes ao valor real medido.

Desse modo, na mensuração da altura de árvores é necessário que o operador tenha conhecimento do funcionamento e prática de operação dos celulares e aplicativos, realizando treinamentos prévios, intensos e aperfeiçoados para cada tipo de equipamento, visando minimizar erros para melhorar a exatidão na estimativa da altura (SILVA et al., 2012; MAYRINCK et al., 2016; CURTO et al., 2018), principalmente de erros não aleatórios.

Portanto, em vista dos apontamentos, o objetivo do estudo foi avaliar a precisão de celulares, aplicativos e operadores na avaliação da altura de árvores em plantio de eucalipto. 


\section{MATERIAL E MÉTODOS}

$O$ estudo foi realizado em plantio de eucalipto (Eucalyptus grandis $\times E$. urophylla, clone H13), no espaçamento $3 \times 3 \mathrm{~m}$, aos 66 meses, localizado em uma propriedade particular (11050'53"S e 55⒊'57"O) no município de Sinop, norte de Mato Grosso, a uma altitude média de 380m (GHENO et al., 2012). Conforme a classificação de Köppen, o clima local é tropical, do tipo $A w$, com temperatura média anual de $25^{\circ} \mathrm{C}$ e precipitação de 1800 a 1900 mm, com duas estações (seca e chuvosa) bem definidas (SOUZA et al., 2013). O solo local é do tipo Latossolo Vermelho-Amarelo Distrófico (VIANA et al., 2015).

A mensuração da altura total $(\mathrm{m})$ das árvores foi realizada em 54 árvores localizadas em 18 parcelas distribuídas sistematicamente na área de plantio, contemplando três árvores aleatórias, por parcela. A altura total real $(\mathrm{m})$ foi obtida de forma indireta, por Hipsômetro Vertex IV ${ }^{\circledR}$, por um operador, já a altura total estimada $(\mathrm{m})$ foi obtida utilizando dois celulares e dois aplicativos por dois operadores. Além disso, realizou-se a medição do diâmetro a 1,30 m do solo (DAP).

Para os celulares, foram selecionados o Motorola modelo Moto G7 Power ${ }^{\circledR}$ e o Samsung Galaxy J7, modelo SM-J700M ${ }^{\circledR}$. O primeiro aparelho possui um display de 6,2 polegadas, câmera de 12 megapixels, sensor acelerômetro de três eixos com resolução de $0,0023956299 \mathrm{~m} \mathrm{~s}^{-2} \mathrm{e}$ sensor giroscópio de três eixos com resolução de 0,0010681152 rad. $\mathrm{s}^{-1}$. Já o segundo aparelho possui display de 5,5 polegadas, câmera de 15 megapixels, sensor acelerômetro de três eixos com resolução de $0,0011971008 \mathrm{~m} \cdot \mathrm{s}^{-2}$ e não possui giroscópio incorporado (TORRES, 2017). Os aplicativos avaliados na mensuração da altura de árvores foram o Measure Height ${ }^{\circledR}$ (versão 1.4) desenvolvido pela Deskis OÜ (2014) e o Hypsometer ${ }^{\circledR}$ (versão 1.11), desenvolvido por Makinosoft (2017), em vista da disponibilidade para download gratuito no sistema operacional Android.

Primeiramente, foi realizada a configuração dos aplicativos quanto à distância do operador à árvore e a altura do olho do operador. Em relação à distância do operador à árvore, foram estabelecidos pontos fixos de observação, sendo a distância desse ponto às árvores obtidas pelo Hipsômetro Vertex IV ${ }^{\circledR}$. No aplicativo Hyspsometer ${ }^{\circledR}$, para o registro da distância, movimentouse lentamente o celular até se atingir o valor da distância registrada pelo Vertex ${ }^{\oplus}$, pressionando assim a tela do aparelho. Já no aplicativo Measure Height ${ }^{\circledR}$, essa distância foi inserida manualmente. Quanto à altura do olho acima do solo, o aplicativo Hypsometer ${ }^{\circledR}$ considera como fixa de
1,60 m, o Measure Height ${ }^{\circledR}$ permite que essa altura seja registrada no aplicativo. No presente estudo, a altura dos olhos dos operadores 1 e 2 foram, respectivamente de 1,45 m e $1,70 \mathrm{~m}$.

Após a finalização das configurações dos aplicativos e o treinamento prático dos operadores na mensuração das árvores usando as tecnologias, iniciou-se a medição da altura total $(m)$ pelo Hipsômetro Vertex IV ${ }^{\circledR}$ e em seguida, a medição da altura total estimada $(\mathrm{m})$ pelos aplicativos Hypsometer ${ }^{\circledast}$ e Measure Height ${ }^{\circledR}$ pelos dois operadores, com os dois aparelhos de celular. Para o primeiro aplicativo, o celular foi direcionado para o ápice da árvore, mantendo-se as mãos estabilizadas e com a estabilização da altura, realizou-se a leitura do valor no aplicativo com o seu registro em planilha. Já para o segundo aplicativo, após a escolha de medir somente altura, o celular foi apontado para que uma "cruz" disponível na tela interceptasse o ápice da árvore, sendo o registro da altura realizado pelo simples toque na tela quando ocorresse essa interceptação, com o registro do valor realizado posteriormente em planilha.

Os resultados da altura total real e estimados foram avaliados quanto à normalidade dos dados pelo teste de Kolmogorov-Smirnov ao nível de $1 \%$ de probabilidade. Em aceitação da normalidade, realizou-se a análise de variância pelo teste $\mathrm{F}$ e a altura total estimada (celulares, aplicativos e operadores) foi comparada a altura total real (Hipsômetro Vertex ${ }^{\circledast}$ ) pelo teste de Dunnett, ao nível de $1 \%$ de probabilidade de erro. Foi ainda avaliada os resultados da estatística descritiva como média, desvio padrão e coeficiente de variação. Já a tendência nas estimativas foi avaliada pela análise gráfica dos erros, análise das estatísticas complementares (Tabela 1) como o viés (V), média das diferenças absolutas (MD), desvio padrão das diferenças (DPD) e raiz do erro quadrático médio (RMSE) relativizados em relação à média a fim de facilitar a comparação entre estimativas, sendo obtido pela divisão dos valores pela média da altura real, multiplicado por 100.

Em relação à distribuição dos resíduos foi considerada ideal a mais homogênea ou com menor tendência de dispersão. Já o Viés indica a tendência em sub ou superestimar os resultados quando esses são respectivamente negativos e positivos, $\mathrm{OMD}$ representa a amplitude dos erros, O DPD indica o quanto homogêneo são os resíduos e por fim, o RMSE demonstra os erros médios. 
Tabela 1. Estatística complementar para avaliação da estimativa da altura de árvores em floresta de eucalipto.

\begin{tabular}{cc}
\hline Estatística & Estimador \\
\hline Resíduo (\%) & $R=\frac{\hat{Y}_{i}-Y_{i}}{Y_{i}}$ \\
\hline Viés (V) & $V=\frac{\sum_{i=1}^{n} \hat{Y}_{i}-\sum_{i=1}^{n} Y_{i}}{n}$ \\
\hline $\begin{array}{c}\text { Média das } \\
\text { Diferenças } \\
\text { absolutas (MD) }\end{array}$ & $M D=\frac{\sum_{i=1}^{n}\left|\hat{Y}_{i-} Y_{i}\right|}{n}$ \\
$\begin{array}{c}\text { Desvio Padrão das } \\
\text { Diferenças (DPD) }\end{array}$ & $D P D=\sqrt{\frac{\left(\sum_{i=1}^{n} d i^{2}-\left(\frac{\sum_{i=1}^{n} d i}{n}\right)^{2}\right)}{n-1}}$ \\
\hline $\begin{array}{c}\text { Raiz do erro } \\
\text { quadrático médio } \\
\text { (RMSE) }\end{array}$ & $R M S E=\sqrt{\frac{\left(\sum_{i=1}^{n}\left(\hat{Y}_{i}-Y_{i}\right)^{2}\right)}{n}}$ \\
\hline
\end{tabular}

$\overline{Y i}=$ valor real obtido pelo Hypsometro Vertex ${ }^{\circledR}$ e $\hat{Y} i=$ valor estimado pelo aplicativo e celular; $n=$ número de observações; e di $=\left(Y_{i}-\hat{Y} i\right)$.

\section{RESULTADOS E DISCUSSÃO}

A altura total real $(\mathrm{m})$ média obtida com o Hipsômetro Vertex IV ${ }^{\circledR}$ foi de $31,04 \mathrm{~m}$, com desvio padrão (DP) de 1,93m e coeficiente de variação (CV) de 6,21\%, já a altura total estimada $(\mathrm{m})$ pelos diferentes celulares, aplicativos e operadores podem ser conferidos na Figura 1.

A altura total $(\mathrm{m})$ real e estimada das árvores de $\mathrm{E}$. urograndis (E. urophylla $\times E$ grandis, clone $\mathrm{H} 13$ ) apresentaram distribuição normal significativa ao nível de $1 \%$ de probabilidade de erro, pelo teste de KolmogorovSmirnorv (K-S d =0,07475 a 0,20142). Observou-se pela análise de variância (F: 46,2470; $p<0.0001$ ) que existe diferença significativa entre a altura total estimada pelos celulares, aplicativos e operadores em relação a altura total real obtida com o Hipsômetro Vertex ${ }^{\circledR}$, ao nível de $1 \%$ de probabilidade de erro. Assim, conforme o teste de médias de Dunett, a diferença significativa ocorreu entre a altura total estimada com o aplicativo Measure Height ${ }^{\circledR}$, em ambos os celulares (Samsung ${ }^{\circledR}$ e Motorola ${ }^{\circledR}$ ) e operadores (1 e 2) em relação a altura total real obtida com o Hipsômetro Vertex ${ }^{\circledR}$, indicando-se assim, no primeiro momento, o uso do Hypsometer ${ }^{\circledR}$ para medição de altura em plantios de eucalipto.

Lauro et al. (2018), em um plantio de clone H13 (Eucalyptus grandis Hill ex Maiden x Eucalyptus urophylla S.T. Blake) cultivado no sistema de Integração LavouraPecuária-Floresta, também verificaram que as médias da altura total estimada com o Measure Height ${ }^{\circledR}$ foram estatisticamente diferentes da média real $(27,39 \mathrm{~m})$ obtida pela mensuração direta das árvores.
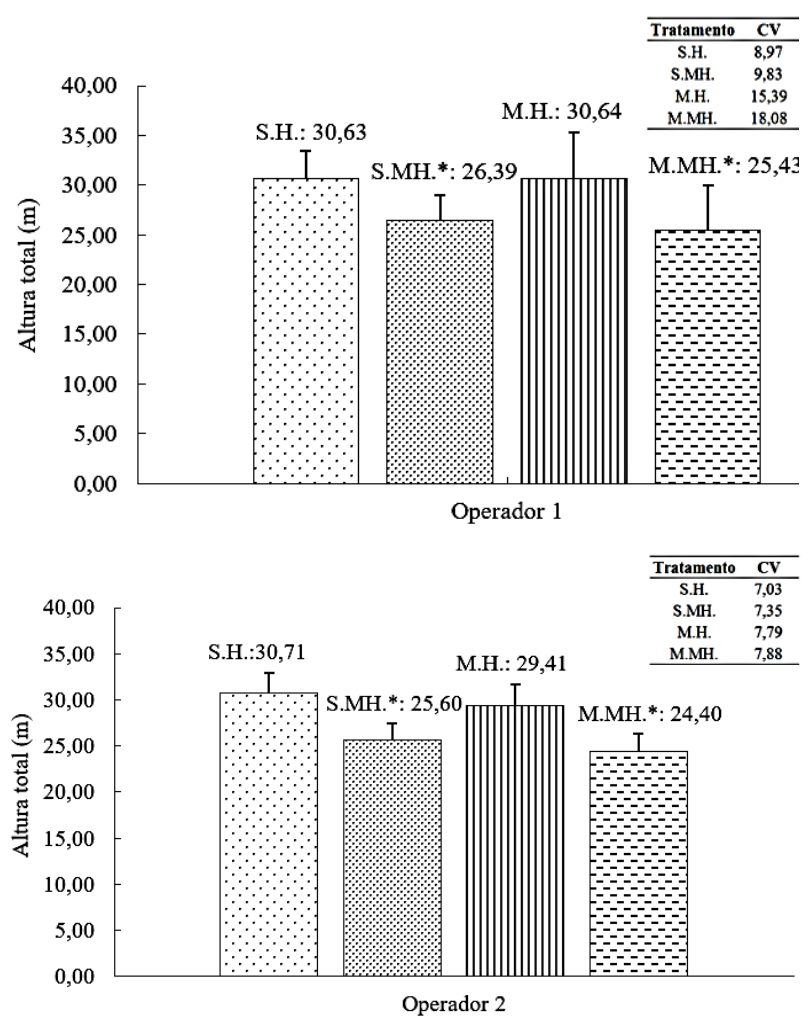

Figura 1. Média (m), desvio padrão (DP) e coeficiente de variação $(\mathrm{CV}, \%)$ da altura total de $E$. grandis $\mathrm{x}$ E. urophylla (clone $\mathrm{H} 13$ ) estimada com os celulares e aplicativos e a real obtida com o aparelho Vertex ${ }^{\circledR}$. Onde S.: celular Samsung ${ }^{\circledR}$; M.: celular Motorola ${ }^{\circledR} ; \quad \mathrm{H} .:$ aplicativo Hypsometer $^{\circledR}$; MH.: aplicativo Measure Height ${ }^{\circledR}$.

Diferentemente, Curto et al. (2019) não observaram diferença significativa ao usar o aplicativo Measure Height ${ }^{\circledR}$ na medição da altura total de árvores em floresta nativa (média de 19,98 m). Isso possivelmente pode ser explicado aos menores valores de média obtidas na floresta nativa, em comparação aos valores obtidos no estudo de Lauro et al. (2018) e no plantio de eucalipto do presente estudo, inferindo sobre a possibilidade sensibilidade do aplicativo na mensuração de árvores mais altas.

Assim, o aplicativo Measure Height ${ }^{\circledR}$, não apresentou estimativas confiáveis da altura total estimada em relação à altura total real, conforme também observado por Lauro et al. (2018), Bijak \& Sarzyński (2015), Villassante \& Fernandez (2014). Já para o aplicativo Hypsometer ${ }^{\circledR}$, Harfouche et al. (2019) também obtiveram desempenho satisfatório para o aplicativo em árvores isoladas de diferentes espécies e em plantio de Eucalyptus spp. A superioridade no desempenho do aplicativo Hypsometer ${ }^{\circledR}$ pode estar relacionada à leitura da altura diretamente no visor do celular sem necessidade de pressionar a tela, mas 
por outro lado deve-se memorizar o valor obtido, visto que a informação não fica registrada. Assim, o movimento ao pressionar a tela, para pausar a medida pode ocasionar erros, conforme ocorre no aplicativo Measure Height ${ }^{\circledR}$ (CURTO et al., 2019). Conforme os autores, a estimativa da altura total em variadas classes para um fragmento de floresta nativa, utilizando o Hyspsometer ${ }^{\circledR}$, resultou em igualdade estatística às medidas do Vertex, comprovando a sua eficiência na área florestal.

Esses resultados estatísticos podem ser validados pela análise gráfica dos resíduos (Figura 2), em que se reafirma que o aplicativo Hypsometer ${ }^{\circledR}$ apresentou melhor precisão da estimativa da altura total das árvores, uma vez que as estimativas no gráfico se encontram muito próximas da linha zero, com menor tendência de variação dos mesmos. Em contrapartida, o aplicativo Measure Height ${ }^{\circledR}$ apresentou tendência de subestimar os valores de altura total das árvores de eucalipto tanto para os dois celulares e os dois operadores.

Isso confirma o resultado da estatística, de que os valores de altura total real não diferem do valor da altura obtida com o Hyspsometer ${ }^{\circledR}$, ao contrário do observado com o aplicativo Measure Height ${ }^{\circledR}$, em que a altura total foi subestimada, diferindo da altura real obtida com o Hipsômetro Vertex ${ }^{\circledR}$.

Reafirmando essa constatação e visando analisar a precisão do celular e do operador, é possível avaliar os resultados das estatísticas complementares (Tabela 2), em que se observa que o Hypsometer ${ }^{\circledR}$ utilizando o celular Samsung ${ }^{\circledR}$, para os dois operadores, teve melhor desempenho na mensuração da altura das árvores por apresentar distribuição de resíduos menos tendenciosa (V) e mais homogênea (DPD), menor erro médio (MD) e menor erro quadrático médio (RMSE), indicando menor diferença entre a estimativa e o valor da altura total obtido com o Vertex ${ }^{\circledR}$. Além disso, confirma-se que o aplicativo Measure Height $^{\circledR}$ no aparelho Motorola ${ }^{\circledR}$ e independente do operador, apresentou maiores amplitudes de erros (MD) e menor homogeneidade dos resíduos (DPD), além de corresponder a erros médios mais altos (RMSE). Já quanto a tendência $(V)$, confirma-se que o aplicativo Measure Height ${ }^{\circledR}$ está subestimando as alturas das árvores.

Além dos aplicativos, as características do celular podem também influenciar no desempenho da medição, sendo possível verificar melhoria na estimativa da altura com o uso de celulares com melhor resolução do sensor acelerômetro (VILLASANTE \& FERNANDEZ, 2014; BIJAK \& SARZYŃSKI, 2015).
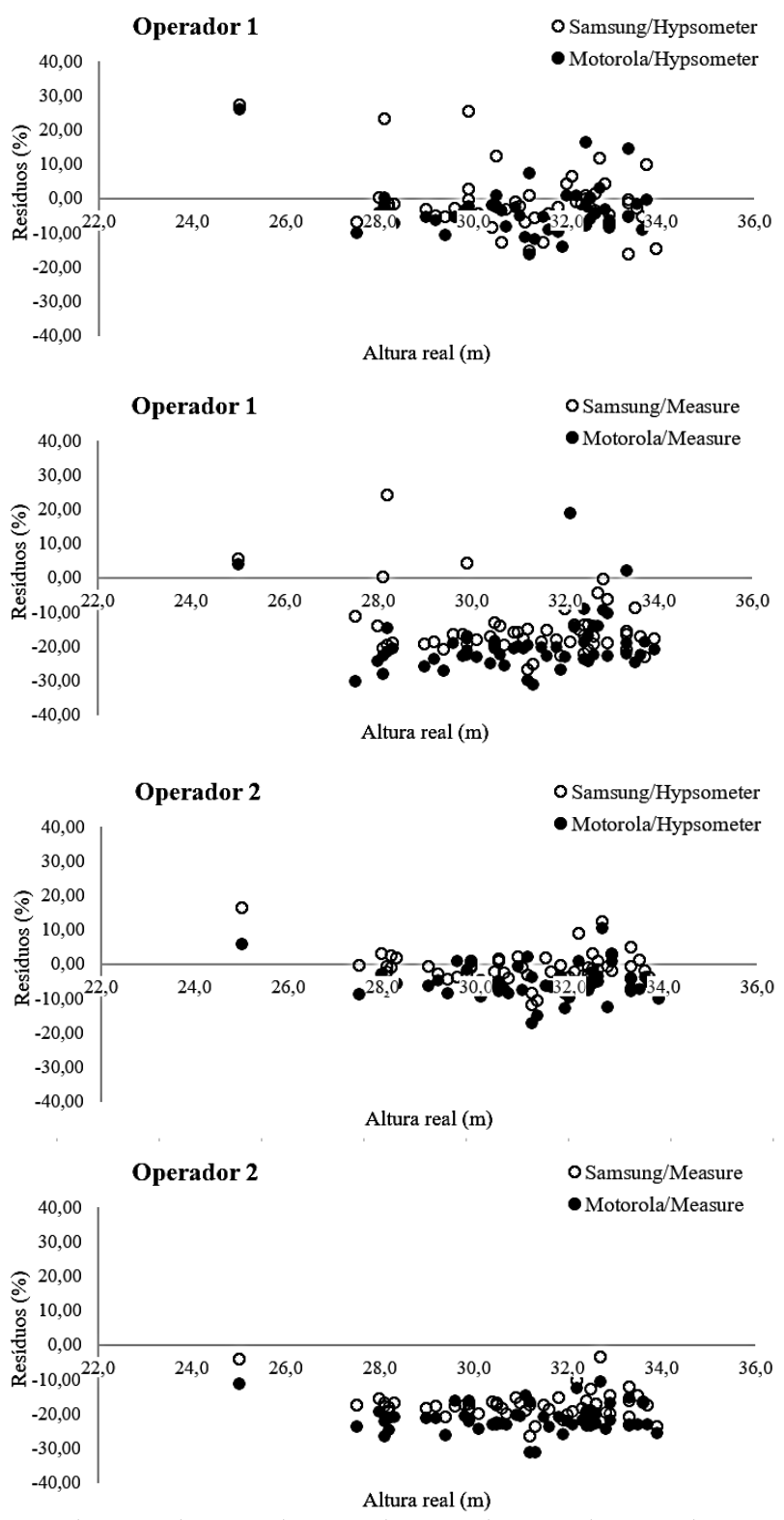

Figura 2. Resíduos (\%) da altura total estimada pelos aplicativos Hypsometer ${ }^{\circledR}$ e Measure Height $^{\circledR} \mathrm{e}$ os celulares modelo Samsung ${ }^{\circledR}$ e Motorola ${ }^{\circledR}$ para os operadores 1 e 2 .

Os aplicativos para mensuração fazem uso de sensores presentes nos celulares, para captar mudanças no movimento, medindo a força da aceleração aplicada ao dispositivo (acelerômetro) sendo possível detectar a posição angular, repassando assim essa informação ao aplicativo, transformando em valores de altura. Em alguns celulares, a rotação (giroscópio) ao longo de cada um dos três eixos pode ser obtida (OLIVEIRA \& GONÇALVES, 2017), medindo-se a velocidade angular, detectando se o aparelho celular for girado no seu próprio eixo, para cima ou para baixo.

De forma combinada esses dois sensores oferecem características encontradas nos hipsômetros 
trigonométricos. Villasante \& Fernandez (2014) testaram dois celulares, para avaliar a precisão da altura obtida por aplicativos, observaram que a presença do giroscópio reduz os erros da estimativa. Assim, dependendo das características dos sensores presentes no celular pode-se obter uma precisão diferenciada para as medições de altura.

Tabela 2. Viés (V), média das diferenças absolutas (MD) e desvio padrão das diferenças (DPD) e raiz do erro quadrático médio (RMSE) relativizado para a altura total de $E$. grandis $\mathrm{x}$ urophylla (E. urograndis, clone $\mathrm{H} 13$ ) medida com diferentes celulares, aplicativos e operadores em relação ao Vertex.

\begin{tabular}{ccccc}
\hline \multirow{2}{*}{ Tratamento } & \multicolumn{4}{c}{ Valores relativos pela média (\%) } \\
\cline { 2 - 5 } & Viés & MD & DPD & RMSE \\
\hline O1.S.H. & $-1,32$ & 5,93 & 8,41 & 8,34 \\
O1.S.MH. & $-14,99$ & 16,14 & 17,18 & 17,14 \\
\hline O1.M.H. & $-1,30$ & 7,99 & 13,66 & 13,53 \\
\hline O1.M.MH. & $-18,07$ & 21,02 & 22,31 & 22,24 \\
\hline O2.S.H. & $-1,09$ & 3,45 & 4,80 & 4,76 \\
\hline O2.S.MH. & $-17,52$ & 17,52 & 17,99 & 17,98 \\
\hline O2.M.H. & $-5,26$ & 6,18 & 7,12 & 7,09 \\
\hline O2.M.MH. & $-21,39$ & 21,39 & 21,81 & 21,80 \\
\hline
\end{tabular}

01: operador 1, O2: operador 2, S.: Samsung ${ }^{\oplus}$; M.: Motorola ${ }^{\oplus}$; H.: aplicativo Hypsometer ${ }^{\circledR}$; MH.: Measure Height ${ }^{\circledR}$.

No presente estudo, ao utilizar o Hypsometer $^{\circledR}$, o desempenho reduziu quando se utilizou aparelho com presença de giroscópio (Motorola ${ }^{\circledR}$ ). Com o Hypsometer ${ }^{\circledR}$ não há como inserir a distância digitando no aplicativo, assim, deve-se movimentar o aparelho celular lentamente, uma vez que há oscilação de valores na tela, até que se encontre o valor igual ao da distância que se pretende registrar. A oscilação tende a ser mais rápida dependendo das características do celular, visto que o sensor giroscópio permite detectar a movimentação do celular entre seu próprio eixo e para cima e para baixo, o que dificulta o registro da distância exatamente igual a real. Assim, para o aplicativo Hypsometer ${ }^{\circledR}$ o aparelho que possui giroscópio tende a resultar em maiores erros. Contudo, essa constatação difere da afirmação de Bijak \& Sarzyński (2015) e Villasante \& Fernandez (2014) que celulares com a presença do giroscópio apresentam estimativas mais precisas da altura total, além é claro da maior resolução do acelerômetro.

Em relação ao desempenho dos operadores, o operador 2, por ter uma altura $(1,7 \mathrm{~m})$ mais próxima da altura do olho fixada pelo aplicativo, promoveu a obtenção de estimativas da altura total com celulares mais próxima ao valor da altura real obtida com o Hipsômetro Vertex ${ }^{\circledR}$. Além disso, as diferenças de desempenho dos operadores no presente estudo, não está associado a distância dos mesmos em relação a árvore, uma vez que ambos realizaram a medição da altura na mesma posição de medição, sempre afastados da árvore a uma distância superior à altura da árvore e ambos receberam treinamento prático sobre os celulares e aplicativos utilizados nessa avaliação antes da medição definitiva.

\section{CONCLUSÃO}

O aplicativo Hypsometer ${ }^{\circledR}$ é preciso na mensuração da altura de árvores em plantio de eucalipto (Eucalyptus grandis $\mathrm{x}$. urophylla, clone $\mathrm{H} 13)$.

O celular Samsung ${ }^{\circledR}$ foi o mais eficiente na estimativa da altura total de árvores utilizando o aplicativo Hypsometer $^{\circledR}$.

O operador 2 gera uma estimativa da altura total mais próxima da altura real, por ter uma altura $(1,7 \mathrm{~m})$ mais próxima da altura do olho do fixada pelo aplicativo.

Empregar tecnologias na mensuração florestal deve considerar as características dos celulares, como os sensores, bem como as características dos aplicativos e a habilidade do operador.

\section{REFERÊNCIAS}

BIJAK, S.; SARZYNSKI, J. Accuracy of smartphones applications in the field Measure of tree height. Folia Forestalia Polonica, v.57, n.4, p.240-244, 2015.

BOŽIĆ, M. et al. Efficiency of ultrasonic Vertex III hypsometer compared to the most commonly used hypsometers in Croatian forestry. Croatian Journal of Forest Engineering, v.26, n.2, p.9199, 2005.

CURTO, R.A. de. et al. Operacionalidade de aplicativos de smartphone para mensuração de altura de árvores em região de ecótono Cerrado-Amazônia. Nativa, v.7, n.2, p.218-225, 2019.

CURTO, R.A. et al. Treinamento na estimativa da altura de árvores de grande porte em floresta inequiânea. Scientia Agraria Paranaensis, v.17, n.2, p.170-176, 2018.

DESKIS OU. Measure height. 2014. Disponível em: https://play.google.com/store/apps/details?id=ee.deskis. androi d.height

FELICIANO, M.E. et al. Avaliação de diferentes hipsômetros na estimativa da altura total. Revista Verde de Agroecologia e Desenvolvimento Sustentável, v.11, n.2, p.1-5, 2016.

FINGER, C.A.G. Biometria Florestal. Santa Maria: Universidade Federal de Santa Maria, 2006.

GICHAMBA, A.; LUKANDU, I.A. A model for designing m- 
agriculture applications for dairy farming. The African Journal of Information Systems, v.4, n.4, p.120-136, 2012.

HARFOUCHE, T.B. et al. Uso de aplicativos em Smartphone para medições de árvores. Biofix Scientific Journal, v.4, n.1, p.7-15, 2019.

LAURO, A.C. et al. Operacionalidade de instrumentos na obtenção de altura total de árvores em sistema agrossilvipastoril. Advances in Forestry Science, v.5, n.4, p.445-451, 2018.

MAKINOSOFT. Hypsometer. 2017. Disponível em: https://play.google.com/store/apps/details?id=makino.android. hypsometer

MAYRINCK, R.C. et al. Avaliação de hipsômetros e operadores na mensuração de árvores de Eucalyptus urograndis de tamanhos diferentes. Revista Verde de Agroecologia e Desenvolvimento Sustentável, v.11, n.5, p.90-94, 2016.

OLIVEIRA, W.S.; GONÇALVES, E.N. Implementação em c: filtro de Kalman, fusão de sensores para determinação de ângulos. Forscience, v.5, n.3, p.1-18, 2017.

SANTOS, T.A. et al. Equação de volume e relação hipsométrica em plantio de Ocotea porosa. Pesquisa Florestal Brasileira, v.32, n.69, p.13-21, 2012.

SILVA, G.F. et al. Avaliação de métodos de medição de altura em florestas naturais. Revista Árvore, v.36, n.2, p.341-348, 2012.

SILVA, L.A.; SOARES, J.J. Composição florística de um fragmento de floresta estacional semidecídua no município de São Carlos-SP. Revista Árvore, v.27, n.5, p.647-656, 2003.

SOARES, C.P.B. et al. Dendrometria e Inventário Florestal. 2.ed. Viçosa: UFV, 2011.

SOUZA, A.P. et al. Classificação climática e balanço hídrico climatológico no estado de Mato Grosso. Nativa, v.1, n.1, p.3443, 2013.

TORRES, M. Phone Tester. 2017. Disponível em: https://play.google.com/store/apps/details?id=com. mtorres. ph onetesterpro\&hl=en_US

URBANO, E. et al. Comparação de diferentes equipamentos para medição da altura de árvores em plantio de eucalipto. Atualidades em mensuração florestal. Curitiba: UFPR, 2014.

VIANA, J.H.M. et al. Caracterização dos solos do sítio experimental do Projeto Safrinha em Sinop-MT. Embrapa: Sete Lagoas, 2015.

VILLASANTE, A.; FERNANDEZ, C. Measurement errors in the use of smartphones as low-cost forestry hypsometers. Silva Fennica, v.48, n.5, p.11, 2014.

Recebido em 23-06-2021 Aceito em 16-08-2021 